\title{
QUANTITATIVE ANALYSIS OF DEMAND FOR RESTORATION SERVICES IN JELGAVA OLD TOWN QUARTER DEVELOPMENT EXAMPLE
}

\author{
Andrejs Lazdins ${ }^{1}$, Dr.oec. / assistant professor; Liga Jankova ${ }^{2}$, Dr.oec. / assistant professor; \\ Madara Dobele ${ }^{3}$, Mg.art; MBA / lecturer; Aina Dobele ${ }^{4}$, Dr.oec. / professor \\ $1,2,3,4$ Latvia University of Life Sciences and Technologies
}

\begin{abstract}
The purpose of the article "Quantitative Analysis of Demand for Restaurant Services in Jelgava Old Town Quarter Development Example" is to find out the demand for restoration service in Jelgava Old Town Quarter and to determine the factors influencing the development of the service. The study uses a qualitative method of demand estimation through a survey and using significance scale. The survey was attended by museum professionals from the region and other stakeholders. The restoration service is much needed, but there is a lack of restorers and there is insufficient funding to spend on restoration. The survey results clearly show that there is a high demand for all types of restoration because of the large number of items to be restored. Respondents value the need to preserve the cultural heritage, the importance of scientific research, the high quality of restoration services, but less importance on the importance of education. Crafts are a way of preserving and passing on to the next generation the cultural values that have been accumulated, maintained and restored. The main factors influencing the demand for restoration are the availability of information and specialists; services provided by restoration workshops; access to finance; demand for cultural and historical heritage.
\end{abstract}

Key words: demand, restoration, qualitative analysis, development.

JEL code: R12

\section{Introduction}

Restoration is an important process of preserving and maintaining cultural and historical sites. By definition, restoration is the scientifically sound restoration of a monument or part of it in its original form, preserving the most valuable layers (Cabinet Regulation No. 474, 2003).

The purpose of this article is to evaluate the demand for the restoration service and to determine the factors influencing its development. Main tasks: to evaluate the importance of restoration in the cultural-historical context; to describe the experience of Kuldiga Restoration Centre; to evaluate the perspective of demand for restoration services and influencing factors in Jelgava Old Town. Quantitative method of demand research was used to evaluate the demand for restoration service. Research methodology is based on the collection of first-time data using questionnaires (Praude V., 2010). The questionnaire has been developed for restoration services with a significance scale of answers from 1 to 10 , where 1 - insignificant qualitative indicator; 10 - significant qualitative indicator; 5 is the mean with a tendency to decrease in significance, while 6 is the mean with a tendency to increase in significance.

Currently, the following restoration specialties exist in Latvia: restoration of monumental painting; restoration of painting; restoration of monumental decorative sculpture objects; graphic restoration; restoration of manuscripts, documents, books and other paper products; polychrome wood, decorative wood sculpture restoration; restoration of gilding; restoration of joinery products construction; restoration of furniture and other interior fittings; restoration of ceramic, glass and porcelain products; restoration of archaeological material; leather, parchment restoration; fabric restoration; restoration of stone and other silicate objects; metal product restoration; organ restoration; physic-chemical and biological research of cultural and historical objects; research of art and antiques (Qualification of restorers., 2020). The study analyses the demand for ceramic, textile and metal restoration.

Cultural heritage issues are important for public education and business development, so the restoration of historic sites in the urban environment is important (Murniece B., 2010; Pukis M., 
2011). In its turn, the development of crafts provides a tradition of preservation and transfer of cultural heritage in regions and cities (Jankova, L., Lazdins, A., Auzina, A., 2018). Preserving historical values is important for sustainable development because heritage teaches us to value what we have achieved and to use it for our future goals (Divandari, J., Danaeinia, A., Izadi, P. 2017).

Restoration is supported and promoted by the Latvian Association of Restorers, which was founded in 1989 and plays an important role in providing restoration services (Qualification of restorers, 2020).

Evaluating the number of restorers in Latvia, it can be concluded from the number of existing members and their specialization that there is a shortage of specialists in restoration (Table 1). This could also be affected by the continuing underfunding of museum collections and restoration, but this is a matter of separate study.

Table 1

Members of the Latvian Association of Restorers - restorers by 2020

\begin{tabular}{|l|l|c|}
\hline \multicolumn{1}{|c|}{ Restoration specialty } & \multicolumn{1}{c|}{ Specialization } & $\begin{array}{c}\text { Number } \\
\text { of }\end{array}$ \\
\hline $\begin{array}{l}\text { Restoration of ceramic, glass and } \\
\text { porcelain products }\end{array}$ & Ceramic and glass restorer & 1 \\
\hline Textile restoration & Textile restorer & 2 \\
\hline \multirow{4}{*}{ Metal product restoration } & Metal restorer - specialist & 1 \\
\cline { 2 - 3 } & Metal product restorer & 2 \\
\cline { 2 - 3 } & Archaeological material and metal restorer & 1 \\
\cline { 2 - 3 } & $\begin{array}{l}\text { Restorer of archaeological material and metal } \\
\text { products }\end{array}$ & 1 \\
\cline { 2 - 3 } & $\begin{array}{l}\text { Master restorer of metalwork and } \\
\text { archaeological material }\end{array}$ & 1 \\
\cline { 2 - 3 } & Metal restorer & \multirow{2}{*}{1} \\
\hline
\end{tabular}

Source: the author was created according to the data of the Latvian Association of Restorers.

In order to understand the market strategy of restoration services, Kuldiga Restoration Centre (KRC) has been briefly analysed. For example, one of the restorations centres with the widest range of services is the Kurzeme Region Kuldiga Restoration Centre, whose main goal:

- to ensure the preservation of the authenticity of Kuldiga historical heritage for future generations.

- ensure the inheritance of craft traditions and the sustainability of historical craft skills.

The main work of the restoration centre is related to the restoration of wooden structures and their wooden elements (as well as metal elements).

Its restoration services are the restoration of joinery elements; advising citizens, building owners and operators; replenishment and use of the "Material Bank"; research of historic buildings; possibility to use the restoration centre workshop premises and tools to perform restoration of wooden joinery elements.

The tasks of the Kuldiga Restoration Centre are:

- advise residents and downtown building owners on building conservation and restoration issues;

- to raise public awareness of the historical values of Kuldiga;

- popularize Kuldiga values to Latvian and foreign residents;

- carry out practical restoration work on wooden joinery;

- survey of historical buildings in Kuldiga municipality;

- identify urgent work on preserving buildings in the Old Town to prevent the destruction of particularly unique details;

- to attract financing from Latvian and foreign funds to facilitate research and restoration work; 
- to ensure co-operation with Latvian and foreign experts;

- continue work on the replenishment of the "Material Bank" (Kuldiga Restoration Centre, 2020).

\section{Research results and discussion}

Jelgava city specialists have previously conducted a survey of potential restoration service users. The survey results show that museum collections contain many artefacts that should be researched and restored (according to unpublished data).

At the beginning of the survey, a questionnaire was developed to analyse the demand for restoration services, and museums and other stakeholders (collectors, churches, etc.) were surveyed. Of the 35 questionnaires sent and distributed, 25 were answered, which can be considered an enough answer, as it covers $71.4 \%$ of all respondents.

Mapping the submitted responses by significance gives a positive overall significance (Table 2). The significance of the answers consists of two fields, a right field with a significance of 6 to 10 and a left field with a significance of 1 to 5 . The dominance of the significance of the survey question is located on the right-hand side of the field, amounting to $187(83.0 \%)$, while in the left-hand field, defined as being low or non-significant overall, the significance is $37(17.0 \%)$. So the overall significance of the answers is significant and noteworthy.

All questions concerning the area of restoration are divided into four groups ( $1 \mathrm{G} ; 2 \mathrm{G} ; 3 \mathrm{G}$ and $4 \mathrm{G}$, see Table 2). The first group consists of questions 1 to 3 and includes a topic on preserving historical objects and obtaining information. The second set of questions from questions 4 to 7 covers the importance of particular types of restoration. The third set of questions, from questions 8 to 11 , covers the topic of access to restoration services. The fourth group, from questions 12 to 15 , covers the perspective of restoration and the importance of education.

Table 2

\section{Survey summary on importance of restoration services}

\begin{tabular}{|c|c|c|c|c|c|c|c|c|c|c|c|c|}
\hline \multirow{3}{*}{ No. } & \multirow{3}{*}{\multicolumn{2}{|c|}{ Survey questions }} & \multicolumn{10}{|c|}{ Significance } \\
\hline & & & 1 & 2 & 3 & 4 & 5 & 6 & 7 & 8 & 9 & 10 \\
\hline & & & \multicolumn{5}{|c|}{ Low significance (left field) } & \multicolumn{5}{|c|}{ Good significance (right field) } \\
\hline 1. & \multirow{3}{*}{$1 \mathrm{G}$} & $\begin{array}{l}\text { Importance of restoration in preservation of cultural and } \\
\text { historical heritage }\end{array}$ & 0 & 0 & 0 & 0 & 0 & 1 & 1 & 6 & 4 & 13 \\
\hline 2. & & $\begin{array}{l}\text { Research of restoration objects as a source of historical } \\
\text { information }\end{array}$ & 0 & 0 & 0 & 0 & 0 & 3 & 1 & 7 & 8 & 6 \\
\hline 3. & & $\begin{array}{l}\text { Feasibility study of restoration objects as a source of } \\
\text { information on volume and cost of restoration }\end{array}$ & 0 & 0 & 0 & 0 & 2 & 4 & 4 & 7 & 4 & 4 \\
\hline 4. & \multirow{4}{*}{$2 \mathrm{G}$} & $\begin{array}{l}\text { Preservation, research and restoration of woven items } \\
\text { (fabrics) }\end{array}$ & 0 & 0 & 0 & 2 & 0 & 5 & 5 & 9 & 2 & 2 \\
\hline 5. & & Preservation, research and restoration of metal objects & 0 & 0 & 0 & 1 & 3 & 2 & 7 & 8 & 2 & 2 \\
\hline 6. & & Preservation, research and restoration of ceramic objects & 0 & 0 & 1 & 2 & 1 & 4 & 6 & 7 & 2 & 2 \\
\hline 7. & & $\begin{array}{l}\text { Preservation, research and restoration of glass (stained } \\
\text { glass) articles }\end{array}$ & 0 & 0 & 1 & 1 & 3 & 3 & 2 & 7 & 5 & 3 \\
\hline 8. & \multirow{4}{*}{$3 G$} & Availability of restoration services & 0 & 0 & 0 & 2 & 3 & 4 & 5 & 3 & 3 & 4 \\
\hline 9. & & Quality of existing restoration services & 0 & 0 & 0 & 0 & 1 & 2 & 3 & 3 & 9 & 7 \\
\hline 10. & & Prices for existing restoration services & 0 & 0 & 0 & 1 & 4 & 2 & 2 & 5 & 6 & 5 \\
\hline 11. & & Topicality and demand of restoration services in the & 0 & 0 & 0 & 0 & 4 & 5 & 5 & 8 & 2 & 1 \\
\hline 12. & \multirow{4}{*}{ 4G } & $\begin{array}{l}\text { Prospects for restoration as an important cultural heritage } \\
\text { preservation service for the next 5-10 years }\end{array}$ & 0 & 1 & 0 & 0 & 1 & 3 & 2 & 7 & 4 & 7 \\
\hline 13. & & $\begin{array}{l}\text { How important is the organization's strategy for } \\
\text { preserving cultural heritage? }\end{array}$ & 1 & 0 & 1 & 0 & 3 & 0 & 3 & 8 & 3 & 6 \\
\hline 14. & & $\begin{array}{l}\text { How important is education for young people about } \\
\text { restoration? }\end{array}$ & 1 & 0 & 2 & 0 & 3 & 3 & 4 & 7 & 3 & 2 \\
\hline 15. & & $\begin{array}{l}\text { How important is the function of educating citizens about } \\
\text { restoration? }\end{array}$ & 1 & 0 & 1 & 1 & 1 & 4 & 6 & 7 & 2 & 2 \\
\hline
\end{tabular}

Source: developed from survey data

The significance of the answers in the first group $(1 \mathrm{G})$ of questions is dominated by right side of field answers - the answers are significant and make up 73 (97.3\%), while in the left-hand side the significance is $2(2.7 \%)$, which means the answers are insignificant (Fig. 1). The significance of the 
restoration in the cultural-historical context accounts for a significance with ratio of $100.0 \%$, which is very significant. Research on restoration items as a source of historical information accounts for a significance ratio of $100.0 \%$, which is significant. The feasibility study of restoration objects as a source of information on volume and cost of restoration represents a significance ratio of $92.0 \%$ to a low significance of $8.0 \%$ (Fig. 1).

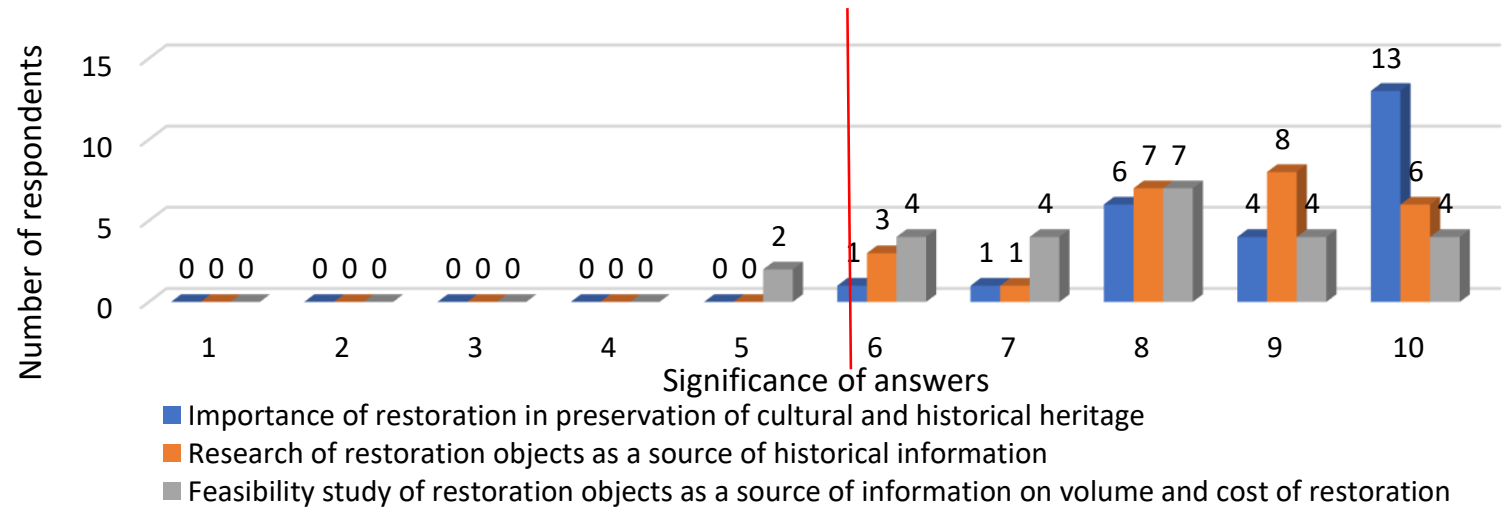

Source: developed from survey data

Fig. 1. Summary of question group "Preservation of Historic Objects"

The significance of the answers focuses around significance values of 8 to 10 , which can be considered as very significant questions related to restoration in the respondents' answers. The significance indicators of the third question (feasibility study of restoration objects as a source of volume and cost of restoration) are somewhat diffused, which can be explained by the risk of forecasting perspective, or relatively low probability, but still high in the assessment area.

The second group of questions ( $2 \mathrm{G}$ ) forms the theme of specific restoration objects (Fig. 2).

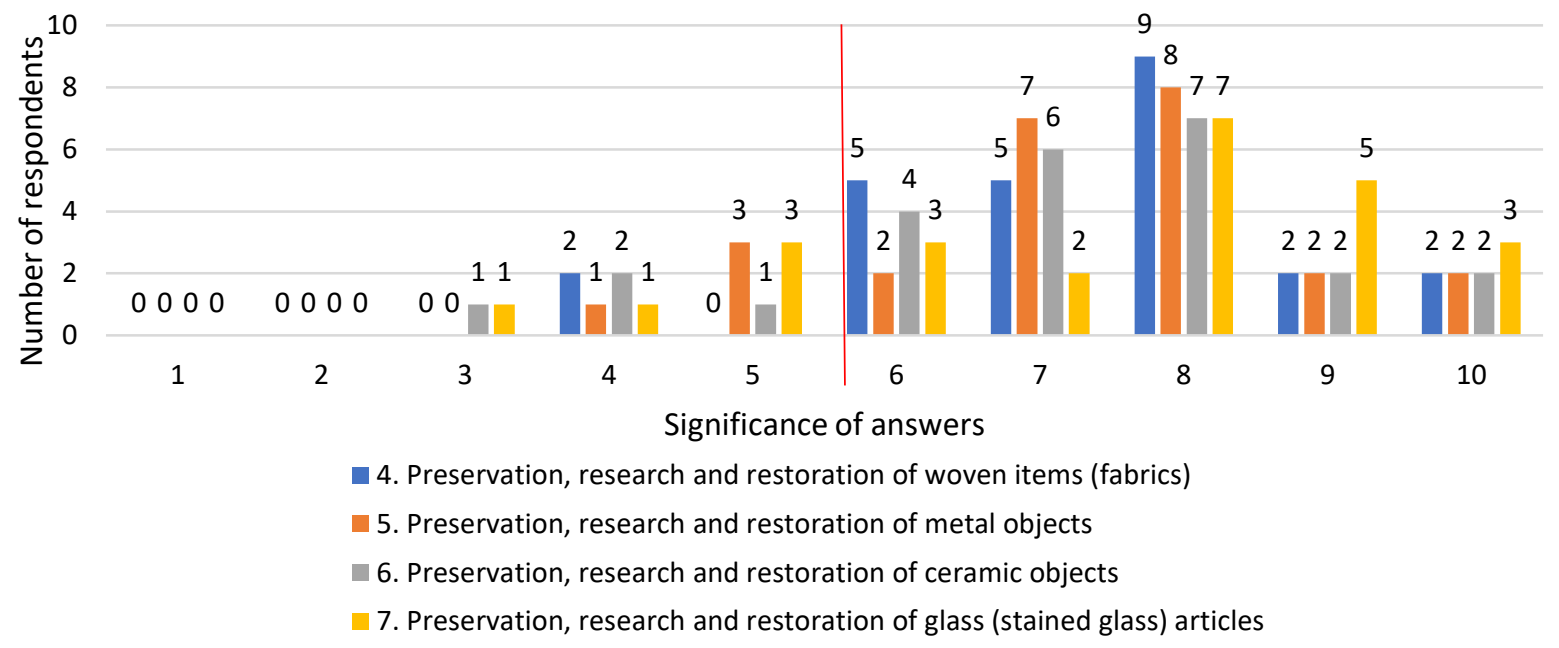

Source: developed from survey data

Fig. 2. Summary of question group "Importance of Restoration of Specific Objects"

The defined right-hand matrix area (high significance) is $85.0 \%$ significant, while the left-hand area (low significance) defined as insignificant $15.0 \%$. Preservation, research and restoration of woven items (fabrics) accounts for a significance ratio of $85.2 \%$, a high significance of $14.8 \%$, a negligible significance. Metal object conservation, research and restoration accounts for the importance ratio $84.0 \%$ - vital importance, but $16.0 \%$ of little significance. Preservation, research and restoration of ceramic items account for a significance ratio of $84.0 \%$ as significant and $16.0 \%$ as insignificant. Glass (stained glass) product conservation, research and restoration made up 
$80.0 \%$ significant importance, but $20.0 \%$ marginal significance. The significance of the questions centres around significance values of 6 to 8 , which can be considered as significant questions related to restoration in the respondents' answers (Fig. 2). There are fewer answers with the highest significance, which indicates that certain restoration objects are not very important, as evidenced by the increase in the number of insignificant answers in the respondents' answers. This group of answers can be interpreted as meaningful; the answers show that the word "restoration" is important, but that certain types of restoration are less meaningful. The results of an earlier study indicate that many artefacts have been accumulated which should be restored but have insufficient financial resources. None of the materials mentioned in the survey dominate, but in general are relevant in the respondents' answers.

The third group ( $3 \mathrm{G}$ ) of claims is made up of the topics of accessibility of restoration services, quality of restoration services, price of restoration services and topicality of restoration services in the context of the exhibition.

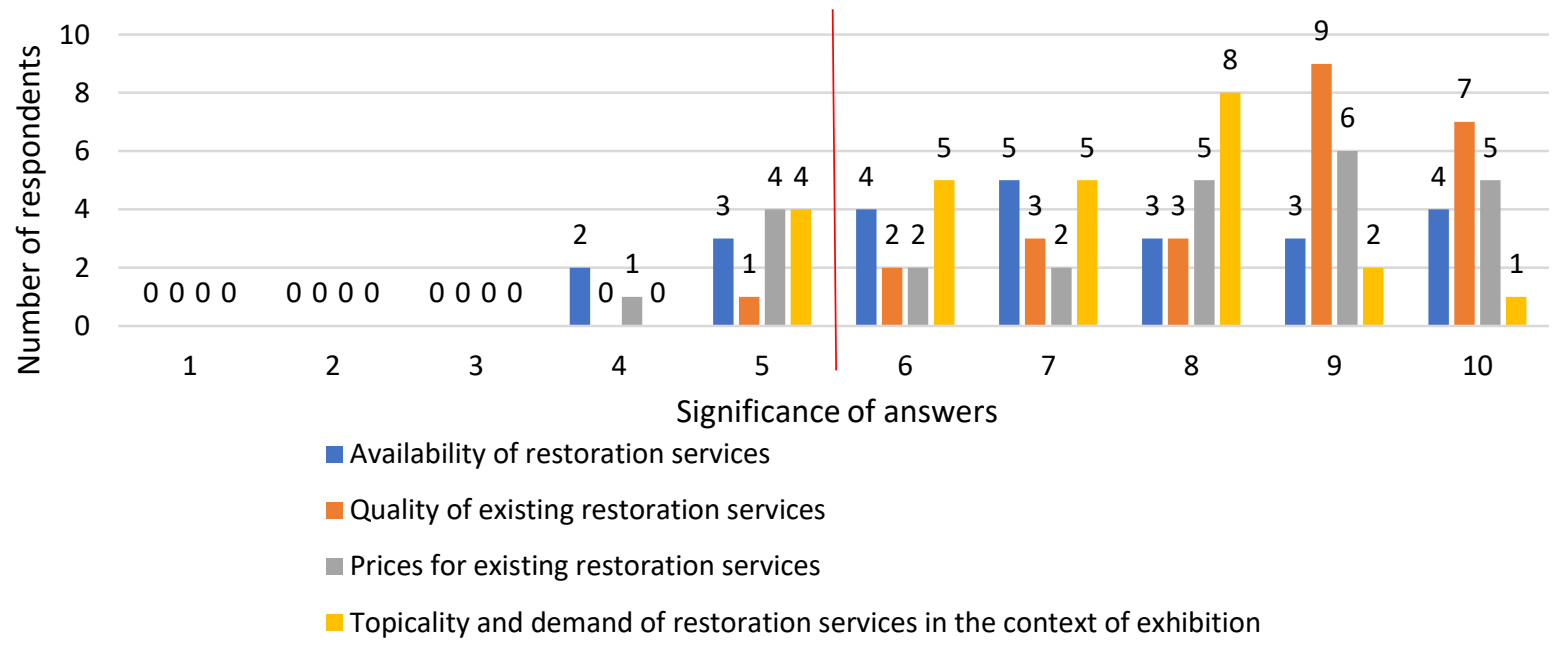

Source: developed from survey data

Fig. 3. The third group of statements, the importance of restoration, strategic direction and education

The defined area of the right-hand matrix, as significant, represents $84.8 \%$, while the left-hand area, defined as insignificant, represents $15.2 \%$. Availability of restoration services accounts for a significance ratio of $84.0 \%$, which is a high significance versus a low significance of $16.0 \%$. The quality of existing restoration services accounts for a significance ratio of $96.0 \%$ significance, but $4.0 \%$ insignificant. Prices of existing restoration services account for a significance ratio of $80.0 \%$, but $20.0 \%$ respondents regard the price as insignificant. Restoration services' actuality and demand in the context of exposure consist of $84.0 \%$ vital importance but make up $16 \%$ low importance. The summary of the significance of the question (Fig. 3) shows that the respondents consider all these questions as significant because the significance scale is dominated by the significance from 6 to 10 .

The statement "Topicality and Demand for Restoration Services in the Context of Exposure" is in a worse position because the overall significant is mediocre with a tendency to insignificant. The availability of restoration services and the cost of restoration services are significantly aligned. The quality of restoration services is of relatively high importance.

The fourth group ( $4 \mathrm{G}$ ) consists of a topic on the cultural and historical significance of the restoration in a 5-10 year perspective, the question of the importance of the strategy for the 
preservation of the cultural and historical heritage in the context of the restoration and education (Fig. 3). The defined area of the right-hand matrix as significant is $83.0 \%$, while the left-hand area defined as insignificant is $17.0 \%$.

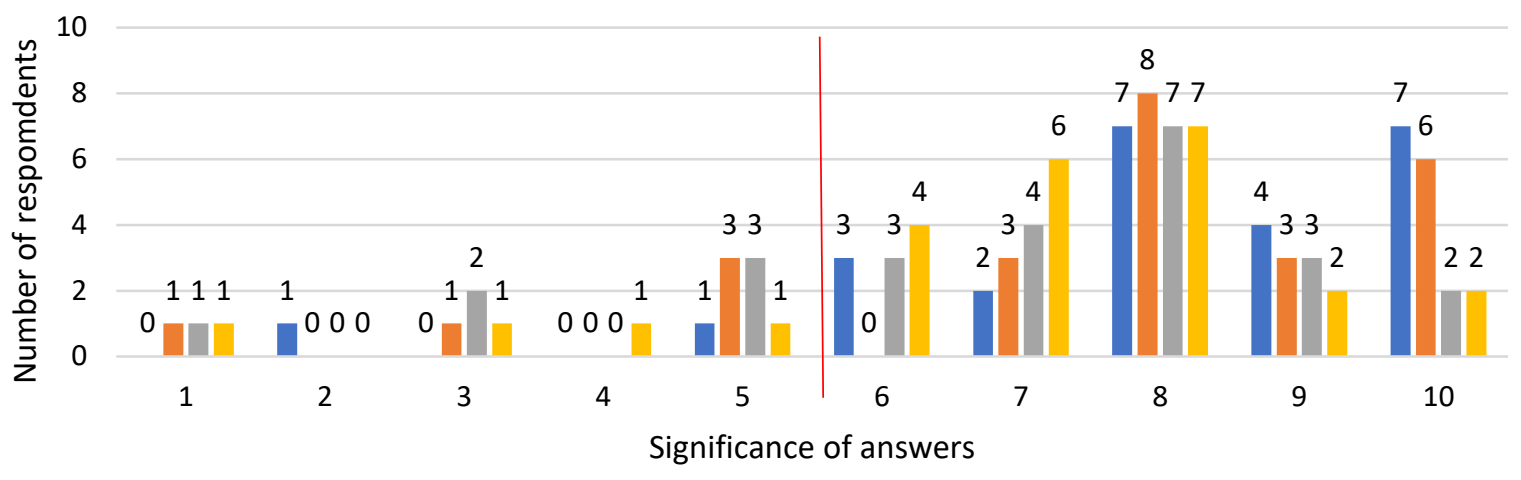

$$
\begin{aligned}
& \text { Prospects for restoration as an important cultural heritage preservation service for the next 5-10 years } \\
& \text { How important is the organization's strategy for preserving cultural heritage? } \\
& \text { How important is education for young people about restoration? } \\
& \text { How important is the function of educating citizens about restoration? }
\end{aligned}
$$

Source: developed from survey data

Fig. 4. Fourth question group, importance of restoration, strategic direction and education

The cultural significance of the restoration over the next 5 to 10 years is constituted by the significance ratio $82.1 \%$, while $17.9 \%$ of the respondents rate it as low significance. In relation to the significance of the strategy for the preservation of the cultural heritage in the context of the restoration, the significance ratio is $80.0 \%$ significant versus $20.0 \%$ insignificant. On the importance of educating young people in restoration, the significance ratios are $76.0 \%$ essential versus $24.0 \%$ insignificant. Regarding the importance of the educational function of the population in restoration, the significance ratio is $84.0 \%$ significant significance versus $16.0 \%$ insignificant significance (Fig. 4).

\section{Conclusions, proposals, recommendations}

1) All respondents' answers to the survey questions and statements provide a common positive and meaningful assessment of the need for a restoration service at the ZPR Centre in Jelgava City.

2) Respondents' assessment of the need to preserve the cultural and historical heritage and the acquisition of information in the context of restorable artefacts is convincingly high, which also indicates the importance of scientific research.

3) When evaluating the material origin of restoration objects, the findings highlight a known problem that may be related to the specificity of museum collections and the availability of restoration, as respondents show little significance.

4) Respondents attach great importance to the availability, quality and cost of restoration, which is an important consideration for planning a restoration budget, raising other funds for the restoration of historic sites.

5) The issue of education is seen by respondents as less important but still relevant. Knowledge of the restoration and the restored object allows a better understanding of its significance in the cultural and historical context but can also be a threat. 
6) From the results of the research it can be concluded that demand is influenced due to limited availability of information and specialists (Table 1); few restoration workshops in the regions (only KRC).

\section{Bibliography}

1. Regulations Regarding the Registration, Protection, Utilisation and Restoration of Cultural Monuments and the Granting of the Status of an Environment-Degrading Object. Cabinet Regulation No. 474 (2003). Retrieved: https://likumi.lv/doc.php?id=78458. Access: 20.01.2020.

2. Praude, V. (2010). Marketing (theory and practice). Book 1. Riga: Burtene, pp. 521.

3. Qualification of restorers. (2020). Retrieved: https://mantojums.Iv/lv/restauratoriem/. Access: 01.02.2020.

4. Latvian Association of Restorers. (2020). Retrieved: https://www.restauratorubiedriba.Iv/biedri. Access: 01.02 .2020$.

5. Murniece, B. (2010). The Role of Cultural Heritage in the Quality of Human Life. Retrieved: http://www.vraa.gov.Iv/uploads/Norvegis/2010.11.26_kulturvesture_B.Murniece.pdf. Access: 01.02.2020.

6. Pukis, M. (2011). Economic and social role of cultural heritage. Retrieved: https://mantojums.Iv/media/uploads/dokumenti/petijumi/pukis_kulturas_mantojums_ekosoc_loma.pdf. Access: 01.02.2020.

7. Jankova, L., Lazdins, A., Auzina, A. (2018). Activity of Master Craftsmen in Latvia. Book Series: Economic Science for Rural Development, Volume: 47., pp. 108- 14. Retrieved: https://llufb.llu.Iv/conference/economi c_science_rural/2018/Latvia_ESRD_47_2018-108-114.pdf. Access: 25.01.2020.

8. Divandari, J., Danaeinia, A., Izadi, P. (2017). Analysis of the Role of Handicraft Production in Rural Sustainable Development: A Case of Sar Aqa Seyyed, Chaharmahal and Bakhtiari Province. Journal of History, Culture \& Art Research / Tarih Kültür ve Sanat Arastirmalari Dergisi. Special issue, Vol. 6 Issue 1, p549-565

9. Kuldiga Restoration Centre. (2020). Retrieved: https://www.kuldiga.Iv/kuldiga/kuldigas vecpilseta/restaurac ijas-centrs. Access: 12.02.2020. 